\title{
CIENCIA Y PÚBLICO EN LA CIUDAD DE MÉXICO EN LA PRIMERA MITAD DEL SIGLO XIX ${ }^{1}$
}

\author{
Luz Fernanda Azuela Bernal \\ Instituto de Geografía-UNAM \\ lazuela@igg.unam.mx \\ Rodrigo Antonio Vega y Ortega Baez \\ Facultad de Filosofía y Letras-UNAM \\ rodrigo.vegayortega@hotmail.com
}

Recibido: 27 julio 2014; Aceptado: 28 abril 2015.

Cómo citar este artículo/Citation: Azuela Bernal, Luz Fernanda y Vega y Ortega, Rodrigo (2015), "Ciencia y público en la ciudad de México en la primera mitad del siglo XIX", Asclepio, 67 (2): p109. doi: http://dx.doi.org/10.3989/asclepio.2015.27

RESUMEN: Entre 1821 y 1860 la Ciudad de México fue escenario de una gran diversidad de actividades de talante científico en las que participó un público heterogéneo que no estuvo restringido a las élites intelectuales y que estableció las bases de una cultura proclive a todo tipo de ciencias. En este trabajo se examinarán sus rasgos a través de la exposición de las diversas actividades científicas de entretenimiento racional y espectáculos cultos que se ofrecieron en el ámbito urbano y que tuvieron como complemento los contenidos de las ciencias difundidos en las numerosas revistas literarias de la primera mitad de la centuria. De esta manera, tanto hombres como mujeres con ciertos recursos económicos, tiempo libre, instrucción más allá de las primeras letras y hábitos de lectura, tuvieron la oportunidad de acceder a los contenidos y los valores de la ciencia de su tiempo, que ellos mismos extenderían a un público más amplio.

PALABRAS CLAVE: Ciencia; Público; Ciudad de México; Prensa; Siglo XIX.

\section{SCIENCE AND THE PUBLIC IN MEXICO CITY IN THE NINETEENTH CENTURY}

ABSTRACT: In the first half of the Nineteenth Century a large diversity of scientific activities were performed in Mexico City, establishing the foundation of a scientific culture. This paper will analyze its features, revealing the numerous activities of rational entertainment and learned performances that were complemented by the scientific contents of many literary magazines published during that time. As a result, the contents and values of Nineteenth Century science were appropriated by men and women of the middle and upper classes, who extended them into the larger public.

KEY WORDS: Science; Public; Mexico City; Press; Nineteenth Century.

Copyright: () 2015 CSIC. Este es un artículo de acceso abierto distribuido bajo los términos de la licencia Creative Commons Attribution-Non Commercial (by-nc) Spain 3.0. 


\section{INTRODUCCIÓN}

Las aproximaciones culturales a la historia de la ciencia han enfatizado que "todo hecho científico, toda teoría o toda práctica relacionada con el conocimiento de la naturaleza es un hecho cultural. Tal y como también es social», y el caso mexicano no es la excepción (Pimentel, 2010, p. 418). La perspectiva cultural hace visible «el papel utilitario y práctico jugado por la ciencia moderna y la ayuda que suponía» para las élites culturales y políticas de los nuevos Estados americanos (Peset, 1987, p. 100). Estos grupos formaban parte activa de los públicos de la ciencia y se desempeñaron como promotores de su difusión hacia el conjunto de la sociedad a lo largo del siglo XIX, de manera que el estudio de las relaciones entre la ciencia y el público resulta indispensable para analizar el proceso de apropiación social de las representaciones y valores de la ciencia, así como las diversas formas de sociabilidad de contenido científico que se expresaron en la Ciudad de México durante el período.

Para abordar este tema puede tomarse como punto de partida el concepto habermasiano de esfera pública, especialmente en lo que concierne a la emergencia de nuevas formas de sociabilidad que se manifestaron en los salones, cafés, sociedades literarias, espectáculos cultos y otros lugares de reunión de los centros urbanos como la ciudad de México. En estos espacios, caracterizados por su espíritu homogeneizante, se pretendía pasar por alto las distinciones derivadas del estatus social y la riqueza, ofreciendo a sus participantes la oportunidad de intercambiar ideas a través del uso de la razón. Una de las manifestaciones más claras de la aparición de la esfera pública fue la proliferación de periódicos y manuscritos a partir del siglo XVIII, en donde se expresaba la "opinión pública», entendida como la voz de la sociedad civil. En estos medios y como producto de las interacciones suscitadas en aquellos espacios surgió el discurso crítico, que se ocupó tanto de la discusión de las políticas gubernamentales, como del establecimiento de criterios para juzgar las obras artísticas y literarias, no menos que las novedades científicas.

Aunque la esfera pública habermasiana ha sido objeto de reconvenciones y ajustes muy pertinentes, también es cierto que en el ámbito historiográfico ha estimulado investigaciones novedosas en las últimas décadas, que han incluido el tema científico (Scott, 1980; López-Ocón, 1998; Broman, 1998; Lynn, 2001; y Bensaude-Vincent 2009). Esto en virtud de que la ciencia fue un elemento crucial en la cultura dieciochesca y decimonónica, que contribuyó a configurar algunas de las formas de sociabilidad de la época y fue a través de sus relaciones con el público que se delineó su autoridad discursiva respecto al conocimiento de la naturaleza.

La introducción de las categorías habermasianas al espacio latinoamericano no ha estado exenta de críticas y precisiones, que no abordaremos en este momento, sin dejar por ello de tomarlas en consideración. En especial, nos parecen oportunas las propuestas de François-Xavier Guerra y Annick Lempérière, quienes prefieren hablar de "la pluralidad de espacios públicos» en donde se verificaron "las modalidades más intelectuales y etéreas de la comunicación y del intercambio de opiniones», a partir de las «relaciones personales, del vecindario, del parentesco y de la pertenencia a las mismas instituciones» (Guerra y Lempérière, 1998, pp. 10-11). Pues en relación con la ciencia y sus diversos públicos, nos interesa manifestar tanto la pluralidad de los espacios científicos y los discursos que de ahí emanaron, como la existencia de una élite que los hizo suyos, con el objeto de hacer explícitos los valores y representaciones de la ciencia que luego hicieron parte de la opinión pública.

\section{LA REPÚBLICA DE LAS LETRAS Y EL PÚBLICO MEXICANO}

A lo largo del siglo XVIII y la primera mitad del siglo XIX la ciudad de México vivió un auge cultural en el que participó un activo grupo de individuos educados en las diversas aulas de instrucción superior de la Universidad, el Seminario Conciliar, el Seminario de Minería, la Academia de San Carlos y el Jardín Botánico, principalmente. Se trataba de una colectividad similar a las que conformaban la República de las Letras de París, Madrid, Boston, Lima o Nápoles, entendida entonces como la «colección de los hombres sabios y eruditos» reunidos en torno a proyectos culturales. En ésta se procuraba el "gobierno de muchos", frente al de uno solo como sucedía en la vida política internacional (Real Academia Española, 1734, Vol. V, p. 586).

La República de las Letras se caracterizó por acoger a aquellos hombres que practicaban las materias del "árbol del conocimiento» y que se daban a conocer mediante impresos o manuscritos donde abordaban sus reflexiones, descubrimientos y polémicas en torno a un tema. La denominación de letrado «englobaba a cuantos tenían algún contacto con ellas, ya fueran autores o no», tanto escritores como lectores que ocuparon en gran número este espacio culto (Álvarez, 2006, p. 19). Era el espacio 
de la "verdadera» democracia basada en el idealismo, de la misma manera que la esfera pública que antes definimos, pero subrayando ahora «la reconstitución de una nueva jerarquía [que ya] no descansaba en el nacimiento o la pertenencia a cuerpos o estamentos privilegiados sino en el capital cultural» (Guerra y Lempérière, 1998, p. 17). Dicho espacio intelectual era concebido como una red no formalizada de personas interesadas en distintas ramas del saber que se caracterizaban «por compartir públicamente el conocimiento y los contactos, y era a todas luces pública» (Munck, 2001, p. 281). Operativamente, la red se sustentaba en diversas reuniones, donde se reflexionaba sobre tópicos de interés común, que luego se divulgaban a un público más amplio a través de revistas y conferencias, a las que nos referiremos más adelante.

Aunque la República de las Letras se proclamaba como un espacio abierto, desde sus orígenes tuvo una serie de restricciones para la pertenencia, a los que se ha referido Hilda Sábato en relación con las élites argentinas. A su juicio, este ámbito letrado tuvo como filtro de ingreso la "selección de méritos» a través de la demostración de las aptitudes de cada individuo, como la «buena pluma», el talento oratorio, los conocimientos eruditos, la conversación culta y las capacidades retóricas, características de una cultura letrada (Sábato, 2007, p. 56).

En lo que concierne a su extracción social, estos republicanos pertenecían a los estratos medio y alto. Sin olvidar en este punto a los funcionarios medios del servicio público, pues en las sociedades donde se retrasó el desarrollo económico basado en la industrialización y el comercio a gran escala, la inserción en la burocracia constituyó un mecanismo de movilidad social y la oportunidad para integrarse a los medios intelectuales (Hobsbawm, 2003, p. 198). De esta manera, algunos miembros de la mediana y alta burocracia y de las profesiones liberales formaron parte de las élites urbanas cultas.

En contraste con las élites culturales, el gran público estuvo conformado por hombres y mujeres de diversas edades; provenientes del ámbito urbano, semiurbano y rural; de clases media y alta; con diversos grados de alfabetización y de instrucción; anhelantes del progreso económico y social con miras al futuro; y con diversas orientaciones políticas. En suma, este público contaba con los recursos económicos y el tiempo disponible para asistir con cierta asiduidad a los diversos actos y espectáculos científicos que se hicieron públicos en la ciudad de México desde el Siglo de las Luces y fueron los lectores de las revistas que abordaremos posteriormente.

\section{LOS ESPACIOS INSTITUCIONALES DE LA CIENCIA EN LA CIUDAD DE MÉXICO}

La conformación del círculo de letrados en México procede del período colonial y alcanzó su punto culminante en el período ilustrado, coincidiendo con la transformación urbana derivada de las reformas borbónicas del último tercio del siglo XVIII. Éstas se sustentaron en un extenso aparato institucional, en el que destacaron los establecimientos científicos de patrocinio real y su vinculación substantiva con diversas entidades metropolitanas.

Las nuevas instituciones mantuvieron un carácter laico y funcionaron como moderna alternativa de la instrucción que se impartía en la Real y Pontificia Universidad de México. Al tiempo que promovieron los intereses sociales y económicos de la Corona, en su seno se propagaron las novedades científicas de su tiempo y se crearon las condiciones materiales para la modernización de la práctica científica novohispana. Nos referimos a la Real Cátedra de Cirugía (1768), el Real Hospital de San Andrés (1770), el Real Seminario de Minería (1779), la Real Academia de las Nobles Artes de San Carlos (1784), el Real Jardín Botánico y la Real Cátedra de Botánica (1787) y el Gabinete de Historia Natural (1790-1802).

Pero más allá de la consecución de sus objetivos académicos, todos los establecimientos impulsaron nuevas formas de sociabilidad a través de la organización de actividades públicas de contenidos científicos, que dieron pie a su apropiación dentro de la cultura dieciochesca. De esta manera estimularon la práctica del "entretenimiento racional» que estaba en boga en las capitales europeas, (Yanni, 2005, p. 24), que se desarrollaba en los confines de sus espacios arquitectónicos y proyectaba en el entorno urbano los valores de la ciencia, al mismo tiempo que establecía un fuerte vínculo entre sus contenidos epistémicos y la vida cultural, como ha explicado Antonio Lafuente respecto a las instituciones científicas madrileñas durante la Ilustración (Lafuente, 1998). El caso novohispano mantuvo algunos paralelismos con el español, como se expondrá enseguida.

El Jardín Botánico de México expresó el propósito de «aficionar al cultivo [de esta ciencia] no sólo a los profesores de Medicina, Cirugía y Farmacia, sino también a todos los curiosos" (Cervantes, 1831, p. 158). Y después de una ceremonia inaugural que provocó cierta polémica, el Jardín se convirtió en un sitio de entretenimiento racional, igual que en un espacio de investigación y enseñanza, a cuyos actos públicos no dejaron de asistir las mismas élites que acogieron el Gabinete de Historia Natural durante su breve vida. ${ }^{2}$ El Real Seminario de Minería, por su 
parte, transmutó ocasionalmente en teatro científico a través de los actos públicos que involucraban el despliegue de instrumentos y máquinas para la ejecución de experimentos mecánicos o químicos ante los ojos expectantes de la sociedad novohispana. También hubo actos públicos en el Real Colegio de Cirugía, aunque éstos recibieron un trato más discreto por su misma connotación. Sin que por ello escasearan los curiosos, pues había oportunidad de presenciar anatomías bajo el sobrio régimen de la ciencia quirúrgica y en el parco ambiente del aula.

Todas estas actividades sirvieron para socializar los valores y representaciones de la ciencia, igual que para difundir su poder para manipular y ordenar los objetos naturales. Esto era particularmente evidente en el Real Jardín Botánico y el Gabinete de Historia Natural donde la naturaleza mantenía un orden racional y estaba sujeta a tal grado de sumisión que se podían observar en un mismo sitio especímenes de territorios remotos y desconocidos (Véase Zamudio, 2011, pp. 39-41). En el Seminario de Minería, por su parte, se hizo pública la artificialización de la naturaleza en el laboratorio y se pusieron a circular el método experimental y sus protocolos como imperativos para verificar hipótesis y extender el crédito de validez del conocimiento.

La importancia que tuvieron estas instituciones, igual que los valores que representaban, fue instrumental en su pervivencia en la época independiente. No hubo gobernante que pasara por alto el interés de la ciencia para el desarrollo del país, ni alguno que quisiera prescindir de sus establecimientos. Y de la misma manera se mantuvo el aprecio de la élite capitalina y los viajeros que visitaron la urbe luego de la ruptura revolucionaria.

Esto quedó de manifiesto durante la presidencia de Guadalupe Victoria (1824-1829), cuando se promulgó la primera Constitución del México independiente (1824), en cuyo artículo 50 de la Sección Quinta, De las facultades del Congreso General, se estableció que el Poder Legislativo tenía la prerrogativa de promover la ilustración: asegurando por tiempo limitado derechos exclusivos a los autores por sus respectivas obras, estableciendo colegios de marina, artillería e ingenieros; erigiendo uno o más establecimientos en que se [enseñaran] las ciencias naturales y exactas, políticas y morales, nobles artes y lenguas («Constitución Federal de los Estados Unidos Mexicanos», 2005, p. 174).

Este artículo constitucional reconoció la necesidad de fomentar los estudios científicos desde el Poder Legislativo Federal a semejanza del impulso que la ciencia española empezó a recibir desde las
Cortes de 1810. Esto sirvió como sustento de los proyectos culturales y educativos de los primeros gobiernos independientes.

Entre las iniciativas políticas para erigir nuevas instituciones científicas resaltamos que el 18 de marzo de 1825 el secretario de Relaciones Interiores y Exteriores, Lucas Alamán (1792-1853), dirigió una carta al rector de la Universidad, expresándole que el presidente Victoria había resuelto inaugurar el Museo Nacional en algunos salones del edificio de dicha corporación. Éste estuvo constituido por las secciones de Historia natural, Antigüedades e Historia, en concordancia con las ideas de Ortiz de Ayala. El primer conservador del Museo fue el Dr. Isidro Ignacio Icaza (¿'?-1834), quien el 15 de junio de 1825 dio a conocer la misión de la nueva institución de albergar, exhibir y custodiar las antigüedades prehispánicas, los especímenes naturalistas representativos de México, los objetos de valor de tiempos coloniales y todas aquellas muestras de la inventiva moderna de los mexicanos (Vega y Ortega, 2014, p. 103).

El proyecto presumía el cometido del Museo como soporte de la instrucción pública y su encargo de difundir los valores morales de la ciudadanía en génesis, expresando al mismo tiempo la voluntad del nuevo régimen de hacer públicos los tesoros que antes habían permanecido en los recintos palaciegos virreinales. Esto último no fue pasado por alto por el público a quien estaba destinado y muy temprano el Museo fue objeto de gran cantidad de donaciones provenientes de diversos puntos de la República, como prueba del interés en la construcción de un espacio laico para la exhibición de los sagrados monumentos y tesoros patrios (Vega y Ortega, 2010, p. 5). Una exhibición, que fue acogida con tal entusiasmo por el público capitalino, que sus asiduas visitas al Museo llegaron a perturbar a los universitarios ${ }^{3}$.

Un segundo proyecto científico de menor alcance público, pero de mayor enjundia cultural, se puso en marcha en 1826 como se expresó en el periódico Águila Mexicana, cuando se anunció la inauguración del Instituto Nacional de Ciencias, Literatura y Artes, un establecimiento único en el país, que de alguna manera recogía la propuesta de Ortiz de Ayala que antes referimos. La ceremonia tuvo lugar en el Aula Mayor de la Universidad, que hizo gala de suntuosos adornos e iluminación para acoger a sus distinguidos miembros y honorables invitados. Los objetivos, expresados en el discurso inaugural de Andrés Quintana Roo, residían «no en enseñar o profesar una ciencia o arte en particular, sino [en] cuidar del adelantamiento y perfección de todas» (Ríos, 1994, p. 5). El Instituto operaría como un órgano director, 
consultor y censor de la cultura y la instrucción para todo el país, mediante la participación de 50 socios de número, 39 correspondientes a 16 estados, 23 del extranjero y 82 honorarios. Se trataba de una iniciativa que manifestaba la disposición del gobierno para hacerse interlocutor de los letrados, que no desaparecería en los años sucesivos, aunque este proyecto no prosperó, como ocurriría con tantos otros durante el aciago diecinueve mexicano.

Respecto a las iniciativas científicas exitosas, en la siguiente década destacó la creación del Instituto Nacional de Geografía y Estadística, fundado el 18 de abril de 1833 como una entidad dependiente de la Secretaría de Relaciones Exteriores e Interiores, donde se tomaron las primeras disposiciones para construir la Carta de la República y levantar la Estadística Nacional. La monumental tarea convocó a los letrados de ese tiempo, quienes hicieron del Instituto la primera entidad que organizó la investigación científica, mientras operaba como el único cuerpo para el desarrollo y la práctica de las ciencias a nivel nacional (Azuela, 2003, p. 159). Y en el mismo año se abrió la Escuela de Medicina que substituyó a la Facultad de Medicina de la Universidad, cuya novedad radicaba en la integración de la Cirugía en la misma profesión, modernizando radicalmente su enseñanza. Casi simultáneamente, se formaron las primeras academias médicas capitalinas, a las que nos referiremos más adelante.

En lo que concierne a sus relaciones con el público, las instituciones educativas que hemos venido mencionando continuaron con la tradición de efectuar exámenes de los estudiantes y disertaciones de catedráticos en los que se admitía la presencia de un auditorio dilecto. Éstos se llevaron a cabo en las décadas de 1820 a 1850 en la Universidad, el Colegio de Minería, la Escuela de Medicina, el Jardín Botánico y el Colegio de San Ildefonso. Y proporcionaron la oportunidad para las mujeres mexicanas, que no tenían acceso como estudiantes, y los jóvenes varones que aspiraban a convertirse en profesionistas, presenciaran la realización de experimentos y demostraciones con instrumental científico, como las que referimos en relación con el período ilustrado.

Se trataba de acontecimientos sociales de gran lustre en los que se combinaban los contenidos científicos con la expresión artística, ya que los discursos de los catedráticos y las demostraciones de los alumnos se completaban con intermedios musicales, como puede advertirse en la ceremonia de fin de cursos de la Escuela de Medicina (1846), cuando el catedrático de Química, Leopoldo Río de la Loza (1807-1876), presentó a las señoritas María de Jesús Zepeda y
Guadalupe Berrueta, ambas de "la mejor sociedad», quienes complacieran al público cantando algunas arias de la ópera de moda, Ernani ${ }^{4}$. (Archivo Histórico de la Facultad de Medicina, en adelante AHFM, 1846, leg. 113, exp. 4, f. 48).

De los muchos discursos pronunciados en aquellos actos, uno de ellos sirve para retratar la metamorfosis de las instituciones de instrucción superior en sedes de sociabilidad científica. Éste correspondió a Joaquín Velázquez de León (1817-1882) y fue publicado en el Anuario del Colegio Nacional de Minería, órgano impreso de la escuela. El reconocido catedrático inició su disertación preguntándose:

¿[si estaban] al alcance de [del Colegio] los grandes progresos que en los últimos años habían hecho las ciencias fundamentales y las auxiliares, de que era inconcuso debía estar instruido el [ingeniero] minero para no perder el tiempo y gruesos capitales en la ejecución de obras erradas y de proyectos inútiles que causaban a veces la ruina de las familias y atrasaban la industria principal de nuestro país? (Velázquez de León, 1849, p. 73).

Los asistentes no debían poner en duda la utilidad del estudio de la Geología y la Zoología entre los ingenieros por cuanto que rocas y animales, «seres inorgánicos y orgánicos estaban mezclados en las entrañas de la tierra, precisamente en el camino que con tanta dificultad emprendía atravesar el minero en sus investigaciones subterráneas». El geólogo expresó que:

el conocimiento de los animales servía para determinar y clasificar los diferentes terrenos que se iban atravesando a medida que más penetraba el minero en el interior de la tierra y que del conocimiento y clasificación de estos terrenos dependía en innumerables casos el acierto y la economía de los trabajos de las minas, al poder fijar en qué formaciones podrían encontrarse los criaderos de las materias metálicas o no metálicas que se querían explotar, las aguas que depositadas en el interior de la tierra se querían utilizar en la superficie y multitud de incidentes y conocimientos que, aprendidos con aprovechamiento, tanto distinguían al teórico-práctico versado en estas ciencias del puramente empírico (Velázquez de León, 1849, p. 74).

Como puede verse, las conferencias doctas sirvieron para legitimar la práctica científica y propagar sus valores, al tiempo que difundían la certeza de que la promoción de las ciencias coadyuvaría al progreso del país, una opinión que compartían las élites cultas con los gobernantes y que era indispensable extender hacia el gran público de la ciudad de México. En todo caso, las instituciones educativas que he- 
mos mencionado parecen desplegarse fuera de las fronteras de su objetivo disciplinar en la atención de un público más vasto y un propósito divulgativo que sin duda excedía sus objetivos pedagógicos. Además, la mera presencia de sus establecimientos en el ámbito urbano dio fe de la importancia que se concedía a las ciencias y, años más tarde, los propios edificios que las albergaban se convertirían en hitos de connotación científica en el espacio citadino. Un hecho que refiere nuevamente a la ciencia y sus públicos.

Como puede apreciarse, durante la primera mitad del siglo XIX la capital nacional contó con una infraestructura científica de carácter público de igual vocación aunque de menor calibre, que las grandes capitales del mundo. De cualquier modo, las instituciones científicas gubernamentales tuvieron una relación suficientemente asidua con el público para sostener los pilares de una cultura proclive a las ciencias que tuvo otras expresiones, como referiremos enseguida.

\section{LAS CIENCIAS EN LAS ASOCIACIONES CULTAS, LOS CAFÉS Y LAS TERTULIAS DE LA CIUDAD DE MÉXICO}

Aunque las instituciones científicas que apuntamos presidieron la publicidad de las ciencias, hubo otros espacios de sociabilidad como las asociaciones letradas, donde éstas se promovieron. De acuerdo con Habermas (1981; citado en Nathans 1990, p. 624), estas asociaciones civiles representaban el ejemplo concreto de integración entre la inteligencia burguesa y los estamentos tradicionales del poder, reunidos con el objeto de impulsar la discusión crítica. Por regla general, se trataba de organismos en donde no se hacía distinción entre ciencias, artes y humanidades, dando lugar a una cultura ilustrada que congregaba todos los ámbitos del conocimiento, en consonancia con el espíritu de las academias y asociaciones europeas de su tiempo.

Así que de la misma manera que ocurría en Europa, en el asociacionismo mexicano predominó la cultura burguesa, la influencia del racionalismo ilustrado y sus derivaciones y antagonismos románticos, así como el afán divulgativo, característicos de las agrupaciones dieciochescas. Como en otros espacios, había inclinaciones moralizantes - y excluyentes - a partir de la imposición de las "buenas maneras» de la burguesía, como la puntualidad, la opinión crítica, la tolerancia intelectual, la moderación, el respeto mutuo, la utilidad frente a la ociosidad y el mérito personal (Peset, 2003, p. 122). Existía además una «idea común» basada en el deseo de saber y transmitir el conocimiento académico entre los «compañeros» (Comellas, 2003, p. 29). No fue extraño que entre los objetivos de las asociaciones se expresara la necesidad de instruir y moralizar a los sectores "populares» y a las "clases menesterosas», como mecanismo indispensable para el progreso de la sociedad mexicana y el adelanto material del país. De manera que en el entorno asociativo, la ciencia operaba como «un conjunto de prácticas asociadas con la resolución de problemas» (Lafuente, 1998, p. 10).

Entre las numerosas sociedades cultas capitalinas de la primera mitad del siglo XIX resaltamos la Sociedad de Amigos del País (1822-1823), la Sociedad de Literatos (1832-1833), el Liceo Mexicano (1835), la Academia de Letrán (1836-1856), el Ateneo Mexicano (1840-1851) el Liceo Hidalgo (1850) y el Círculo Juvenil de Letrán (1857). Éstas también desempeñaron un papel importante en el ámbito científico mexicano, ya que se convirtieron en espacios para la convivencia de los hombres de ciencia junto con historiadores, poetas y políticos. Hubo también asociaciones que convocaron a los profesionales de alguna disciplina, como la Sociedad Mexicana de Geografía y Estadística (1833 hasta el presente), la Academia de Medicina de Mégico (1836-1841), la Academia Farmacéutica de México (1839) y La Unión Médica (1856-1858). Otras agrupaciones culturales de la ciudad de México fueron el Colegio de Abogados, la Junta de Instrucción Pública, la Junta Directiva del Museo y el Jardín Botánico, la Compañía Lancasteriana, la Junta de Mejoras Materiales y la Academia Filarmónica Mexicana, organizada por José Mariano Elízaga (1786-1842) y que constituyó el primer conservatorio formal de Latinoamérica (Zanolli, 2000, p. 6). En términos generales, tal como ha advertido Capel, «en las sociedades creadas tras la independencia el objetivo más frecuente era el de adelantar y propagar [...] el reconocimiento del territorio nacional, la clasificación y el estudio de las producciones naturales [y] la descripción de la naturaleza en su aspecto exterior» (Capel, 1993, p. 412).

Un ejemplo paradigmático de estos espacios de sociabilidad fue el Ateneo Mexicano que contó entre sus miembros a hombres de letras como Lorenzo de la Hidalga, José María Lacunza, José María Lafragua, Andrés Quintana Roo y José María Tornel, junto con destacados hombres de ciencia como Miguel Bustamante, Manuel Carpio, José Gómez de la Cortina e Isidro Rafael Gondra (Azuela y Sabás, 2009, pp. 84-87). Los ateneístas se propusieron organizar conferencias y lecciones públicas gratuitas de diversas especialidades, pues entre sus objetivos destacaba "la instrucción del pueblo» ${ }^{5}$. Las cátedras fueron «muy concurridas por personas de todas edades, clases y condiciones, que con buena voluntad acudieron a este centro cultural para adquirir los conocimientos científicos o artísticos que les interesaban» (Perales, 1957, p. 83). 
A la par del desenvolvimiento de las agrupaciones cultas, la capital del país escenificó un aumento progresivo de establecimientos comerciales que facilitaron la sociabilidad de las élites, en donde se disponía de libros, periódicos y revistas por el precio de una taza de café o un vaso de vino. La clientela tenía la misma composición social que los clubes, logias, academias, sociedades literarias o tertulias semanales que mencionamos (Díaz y de Ovando, 2003, p. 76), aunque cada uno de estos espacios tenía distintos patrones de sociabilidad.

A juicio de Agulhon, «la oposición entre el carácter comercial, público y abierto de un café y el carácter no lucrativo, privado y cerrado de una asociación» convivió en las ciudades de la primera mitad del siglo XIX (Agulhon, 2009, p. 14). Aunque el punto de contacto entre ambos espacios se daba cuando la clientela pertenecía a una agrupación que carecía de su propio salón para efectuar las reuniones, lo que sucedía generalmente en las primeras sesiones de ésta. En estos espacios comerciales y de sociabilidad urbana se podía disfrutar de las horas de ocio entre bebidas estimulantes y cigarros, juegos de billar, cartas y dominó, lectura de periódicos y folletos, largas conversaciones entre amigos y concurrentes. El público del café incluía también estudiantes de las escuelas superiores, en «su mayor parte solteros, y por lo tanto sin responsabilidades familiares [...], entre quienes se [impuso] el hábito del encuentro en los cafés, [que satisfacían] sus nuevas necesidades de sociabilidad en el marco de la comunidad de lugares» (González Bernaldo de Quirós, 2001, p. 71). Aunque se trataba de espacios esencialmente masculinos, también está documentada la existencia de cafés de carácter familiar a donde acudían mujeres y niños.

En todo caso, la literatura de la época ubica las tertulias cultas en los cafés, librerías y boticas, igual que en los salones y bibliotecas particulares y reseña la discusión de los temas de actualidad, la lectura en voz alta, amén del recital musical y la declamación poética. Todo ello como complemento de otras prácticas eruditas, como el coleccionismo naturalista y el registro de observaciones astronómicas y meteorológicas, que se integraban al entretenimiento racional de las élites decimonónicas, como explicaremos a continuación.

\section{LAS CIENCIAS Y EL ENTRETENIMIENTO PÚBLICO EN LA CIUDAD DE MÉXICO}

Aparte de las tertulias y las veladas literarias, las distracciones de las clases privilegiadas incluían la asistencia al teatro para disfrutar operetas y zarzuelas; la participación en carnavales, mascaradas, bailes, ferias, corridas de toros y peleas de gallos; la intervención en los diversos ritos del calendario litúrgico; y la organización de paseos a las áreas ajardinadas de la ciudad, que en ocasiones desplegaron una modalidad cientifista.

Las ciudades decimonónicas de las grandes capitales contaron con áreas dedicadas a este entretenimiento citadino, concebidas por los «urbanistas» occidentales de la época como «espacios arbolados, recreativos, planeados de antemano para ser recorridos a pie, a caballo o en carruaje, que buscaban poner en contacto a los paseantes con la naturaleza» (Hernández Franyuti 2007, p. 102). En la capital eran populares la Alameda y los paseos de origen dieciochesco de Bucareli, Revillagigedo y Azanza, siguiendo la pauta del paseo madrileño de El Prado. Además de la ocasión para encontrarse con sus conocidos, los paseos brindaban la oportunidad de respirar aire fresco -recomendado ampliamente por los higienistas- y de observar la naturaleza en plenitud, amén de la posibilidad de practicar el coleccionismo naturalista.

Esta última actividad era más recurrente en los paseos por los alrededores de las ciudades y las excursiones a bosques y montañas que disfrutaron las élites mexicanas del XIX, igual que las americanas y europeas y cuyo testimonio quedó plasmado en los contenidos geográficos y naturalistas de la literatura del período, así como en las revistas que analizaremos.

Las colecciones científicas privadas con frecuencia se generaron a partir del acopio que se llevaba a cabo en estos paseos y fueron un incentivo para la práctica científica amateur, así como para el desarrollo de formas de sociabilidad relacionadas con la clasificación y el canje de especímenes.

Uno de los testimonios que revela el amplio interés que los miembros de la República de las Letras tuvieron sobre el tema se encuentra en el diario de viaje de Brantz Mayer (1809-1879), abogado y secretario de la Legación estadounidense en México, entre finales de 1841 y los últimos meses de 1842, titulado México lo que fue y lo que es. El texto resalta las colecciones privadas de José Justo Gómez de la Cortina (1799-1860), quien poseía un raro repertorio de armas antiguas y modernas de México y otras partes del mundo que exhibía a sus conocidos. Además, éste había reunido «cierto número de interesantes documentos del país, junto con algunos cuadros originales y copias de los artistas más ilustres de las escuelas» europeas (Brantz, 1953, p. 97).

Otro coleccionista era José Mariano Sánchez y Mora (1777-1845), ex conde del Peñasco, quien poseía un gabinete que constaba de cuatro secciones: 
Antigüedades, Historia Natural, Pintura e Instrumentos de ciencias físicas. "Su colección de monedas con más de tres mil ejemplares, [era] sumamente valiosa, y su Gabinete de Mineralogía [era], sin disputa, el más selecto de la República Mexicana» (Mayer, 1953, pp. 357-358). También Lucas Alamán fue conocido por sus colecciones botánicas y mineralógicas, la primera de las cuales era tan vasta que alcanzó para que el político hiciera un donativo a la Flora General del Globo de Agustín de CandoIle (Alcocer, 1897, p. 20). Seguramente Alamán no fue el único que hizo donaciones de especímenes y colecciones a los museos europeos y estadounidenses, pues ellas formaban parte de la cultura coleccionista. Ésta se conjugó con las visitas a los acervos públicos del Jardín Botánico, el Museo Nacional o el Colegio de Minería, como parte de las actividades sociales de las élites.

También fueron parte de ellas los globos aerostáticos, que habían surcado los aires de la Ciudad de México desde el Siglo de las Luces y que continuaban produciendo entusiasmo entre los capitalinos, tanto por sus connotaciones científicas como por su prodigiosa capacidad de vuelo. En ocasión del ascenso programado para los días 2 y 3 de abril de 1842 en la plaza de toros de San Pablo, el estudiante del Colegio de Minería y tripulante del globo, Benito León Acosta, recibió el apoyo de los catedráticos de dicho establecimiento, convocados por el Ayuntamiento Constitucional de la ciudad de México. En acatamiento de lo dispuesto se nombró a los catedráticos de Química, Manuel Herrera, y de Cosmografía y Delineación, Tomás Ramón del Moral, para "asegurar el buen éxito de la ascensión» (AHPM, 1842, caja 196, exp. 14, f. 5).

La función científica incluía la contemplación del procedimiento "químico para inflar el globo» construido por el estudiante, mismo que fue acompañado por «músicas militares para que [hacer] más agradable el espectáculo». El público estuvo al tanto de las observaciones científicas que se llevarían a cabo durante el vuelo (Citado en Díaz y de Ovando, 1998, pp. 724-725) y tuvo el privilegio de atestiguar el despegue por el módico precio de un boleto, pero una vez fuera los confines de la Plaza de Toros el globo maravilló a todos los citadinos con el encanto de su vuelo.

Como puede verse, en la primera mitad del siglo XIX las ciencias fueron parte de la cultura urbana de las clases media y alta, que además participaban plenamente de la cultura escrita, que en aquellos años había crecido exponencialmente gracias a las novedades tecnológicas que abarataron los procesos editoriales, generando un desarrollo inédito en tal industria.

\section{LOS CONTENIDOS CIENTÍFICOS EN LAS REVISTAS DE LA CIUDAD DE MÉXICO}

La aparición de la prensa periódica estuvo estrechamente vinculada con la esfera pública, entendida como el medio por excelencia para propiciar las expresiones de la crítica y manifestar la opinión pública, fuera ésta política, artística, literaria o científica. Como ha señalado Habermas (1981, p. 84), el nacimiento y ulterior expansión de la crítica que apareció en la prensa de los siglos XVII y XVIII en Inglaterra apuntó al nacimiento de un emergente juicio público que desafió el antiguo monopolio interpretativo del Estado y del clero. De hecho, la transformación de la cultura misma en una mercancía, que se verificó el XVIII tanto en Francia como en otras regiones, hizo asequibles muchos bienes culturales a una colectividad más amplia, expandiendo las fronteras de la esfera pública burguesa para incluir un "público difuso» cuyos miembros sólo necesitaban estar alfabetizados. En este sentido, las publicaciones periódicas que ahora examinaremos, representan un medio privilegiado para apreciar el papel que desempeñó la ciencia en la esfera pública mexicana.

Para abordar el tema de las publicaciones periódicas habría que reconocer sus orígenes en las gacetas de la primera mitad del siglo XVIII, aunque el surgimiento de una prensa propiamente crítica corresponde a una etapa posterior, cuando se dieron a la imprenta los periódicos de Ignacio Bartolache (17391790) y José Antonio Alzate (1733-1799). El primero fue el editor del Mercurio Volante, en el cual la divulgación científica ocupó varias páginas y el segundo publicó en 1768 el Diario Literario de México, que más tarde cambió de nombre a Asuntos Varios sobre Ciencias y Artes, y para 1778 sacó a la luz la Gazeta de Literatura (Véase Saladino, 1996).

En relación con los lectores de estas publicaciones, es preciso reconocer que aunque su número era reducido y se limitaba a un dilecto sector de las clases medias y altas, sus aficiones sentaron las bases para una cultura lectora de impresos periódicos que se desarrollaría con gran dinamismo en todo el siglo XIX y que estaría acompañada por los esfuerzos alfabetizadores que se irían incrementando a lo largo de la centuria, igual que en otras latitudes. La demanda generada por este público se satisfizo mediante el aumento del tiraje, variedad y formato de los impresos publicados por diversas imprentas de la ciudad de México, ya fueran periódicos, revistas, catecismos, almanaques, cartillas, manuales, folletos y calendarios (Suárez, 2005, p. 85). 
En lo que concierne a las revistas literarias ${ }^{6}$, las primeras décadas de vida independiente atestiguaron la existencia de un público suficiente para sostener los proyectos editoriales que se abrieron paso con la primera revista literaria mexicana, publicada en 1826 bajo el título de El Iris. Periódico Crítico y Literario. Se trataba de una publicación destinada para de "servir de distracción y diversión» al público, al tiempo que le proporcionaba instrucción, mediante una variedad de contenidos entre los que se contaban asuntos de Geografía, Historia, Astronomía, Física, Antigüedades, Química, Botánica, así como poemas, cuentos y relatos de viajes. Su línea editorial no fue excepcional, ya que entre 1820 y 1860 las revistas de la ciudad de México contuvieron multitud de escritos referentes a las ciencias, de la misma manera que publicaron las voces de la opinión pública tanto en el orden político y religioso - antes vedado-, como en relación con la crítica literaria, artística y científica.

En cuanto al modelo editorial, las revistas mexicanas no fueron originales, sino que guardaron similitudes con las publicaciones extranjeras de la época, como las españolas El Artista, El Museo de las Familias y El Semanario Pintoresco Español; las francesas Le Cultivateur, Magasin Pittoresque, Le Mosaïque, Musée des Familles y Le Père de Famille; las inglesas The Penny Magazine, The Spectator y Register of Arts; la estadounidense The Family Magazine; y las Memorias de la Sociedad Económica de la Habana y El Quetzal, ambas de Cuba.

La prosa de las revistas se distinguió por una narrativa agradable y un vocabulario sencillo que apelaba al deleite de aquellos lectores que ocupaban algunas de sus horas semanales en su lectura, ya fuera para instruirse o entretenerse. Aquí descollaron los prosélitos del romanticismo, que tuvo también una expresión científica que se plasmó en las revistas, «impulsado por estudiosos desencantados del reduccionismo mecanicista de la llustración y las limitaciones que exhibía para la investigación de la naturaleza» (Azuela, Sabás y Smith, 2008, p. 61). Aunque también es cierto que en las revistas en que se expresó esta corriente se advierten continuidades con un pensamiento racionalista e ilustrado.

Los intelectuales involucrados en la edición de las revistas procuraron hacer comprensibles al público mexicano los textos y autores más destacados, sin distinción de orígenes geográficos, propósito que hicieron explícito en los escritos introductorios que aparecieron en los primeros números de las revistas capitalinas. Aquí conviene incluir un extracto del proyecto editorial de El Mosaico Mexicano, que ex- presó la intención de mostrar al público un cuerpo de escritos de gran calidad literaria en disciplinas científicas, humanísticas y tecnológicas y solicitó a los letrados su colaboración de acuerdo con las siguientes pautas: "El fin [de la revista estaba] reducido a dos palabras: la naturaleza y la industria. Sobre estos objetos [admitirían] todos los artículos que [les] [dirigieran], con tal que [fueran] cortos y de algún interés, quedando este último sujeto a [su] calificación para darles o no lugar en [sus] columnas» (Los Editores, 1836, pp. 1-2).

Entre las revistas editadas en la ciudad de México en la primera mitad de la centuria, mencionaremos algunas que nos parecen especialmente ilustrativas, como el Registro Trimestre. O Colección de Memorias de Historia, Literatura, Ciencias y Artes (1832-1833). El Registro era contemporáneo de las primeras publicaciones especializadas como el Periódico de la Academia de Medicina de Mégico (1836-1842) y el Boletín del Instituto Nacional de Geografía y Estadística (1839). Todas ellas se caracterizaron por el alto número de contenidos científicos y el grado de especialización en el lenguaje, así como por su intención expresa de informar a los lectores sobre los adelantos de las disciplinas que formaban su objetivo editorial.

Dentro de las revistas de amplio espectro, tal vez la más paradigmática del género e indudablemente la de mayor enjundia de los años cuarenta fue EI Museo Mexicano (1843-1846), cuyo cuerpo editorial estuvo compuesto por Manuel Payno, Guillermo Prieto y José María Lacunza, tres de los intelectuales más influyentes del siglo diecinueve mexicano. El carácter de la publicación, que garantizó su amplia circulación entre las élites intelectuales, puede resumirse en los siguientes atributos: solidez ideológica (liberal); excelencia de sus autores y editores; y deliberada intención de incluir noticias y artículos científicos. Estos últimos se refirieron especialmente a la geografía y la historia natural, aunque no estuvieron ausentes ni las matemáticas, la astronomía, la química, la medicina y otras disciplinas.

Como puede advertirse en los ejemplos expuestos, la divulgación de la ciencia fue uno de los objetivos editoriales de las revistas del período, que respondía a la demanda de un público inmerso en una cultura polifacética en la que no estaban ausentes los asuntos científicos. Las revistas, en este sentido, hacían eco de las diversas manifestaciones de la cultura científica que hemos referido, completando la información adquirida en las exhibiciones y conferencias, igual que en los actos públicos de las instituciones de educación superior y en el Museo. 


\section{CONCLUSIONES}

Como se ha podido ver en las páginas precedentes, la ciencia ocupó un lugar preponderante en la vida cultural de la capital mexicana durante el período estudiado. Su desempeño rebasó el ámbito epistémico y alcanzó amplios sectores de la vida social, mostrando que:

"la ciencia no es solo un proceso cognitivo que da cuenta de los fenómenos naturales o sociales, sino implica una actividad humana colectiva, encarnada en artefactos materiales e inseparable de las configuraciones de la realidad social y de los ejercicios del poder» que se materializan en la ciudad (Pohl-Valero, 2012, p. 400).

Las fuentes archivísticas, hemerográficas y bibliográficas analizadas permitieron reconocer las diversas manifestaciones culturales de la práctica científica en los espacios institucionales y en las aulas de instrucción superior, que abrieron sus puertas al público para difundir sus actividades mediante certámenes, discursos y la exhibición de colecciones y actos experimentales, no menos que a través de espectáculos científicos, como los globos aerostáticos, que excedían sus

\section{NOTAS}

1 Esta investigación forma parte del proyecto PAPIIT IN 301113: "La Geografía y las ciencias naturales en algunas ciudades y regiones mexicanas, 1787-1940". Responsable Dra. Luz Fernanda Azuela, Instituto de Geografía-UNAM. También es parte del proyecto PIFFYL (2014-009): “Historia socio-cultural de la ciencia y la tecnología de México, 18211911". Responsable Dr. Rodrigo Vega y Ortega, Facultad de Filosofía y Letras-UNAM.

2 La polémica científica estuvo protagonizada por José Antonio Alzate (novohispano) y Vicente Cervantes (peninsular) a través de catorce escritos publicados en la prensa de la ciudad de México entre febrero de 1788 y agosto de 1789, en especial en la Gazeta de México. La controversia estuvo centrada en la introducción de la nomenclatura linneana en la práctica botánica de Nueva España. Alzate criticó el sistema de clasificación de plantas de Carl von Linné, mientras que Cervantes la defendió. La polémica fue seguida por los lectores de las gacetas novohispanas que expresaban su punto de vista sobre el asunto en las tertulias de la época. Esto es

\section{BIBLIOGRAFÍA}

“Constitución Federal de los Estados Unidos Mexicanos" (2005). En: Tena, Felipe (comp.), Leyes fundamentales de México, 1808-2005, México, Porrúa, pp. 167-195, p. 174.

Agulhon, Maurice (2009), El círculo burgués. La sociabilidad en Francia, 1810-1848. México, Siglo XXI, p. 14. objetivos pedagógicos. En todas estas actividades, igual que en las promovidas por las asociaciones cultas, los letrados fueron pieza clave de la conformación del entretenimiento racional, en el que la población entraba en contacto con una naturaleza domesticada que invitaba a la reflexión científica y se propiciaba la apropiación de los valores y representaciones de la ciencia. Esto último fue particularmente vívido en su desempeño en los numerosos proyectos editoriales destinados a un público amplio, donde dejaron plasmados tanto sus ideales científicos, como su propósito de coadyuvar al progreso del país mediante la promoción de una ciencia útil. Y de la misma manera, pusieron de manifiesto sus esfuerzos encaminados al robustecimiento de una opinión pública, en la que las manifestaciones científicas fueron innegables.

De esta manera, puede concluirse que dentro de la reducida escala que le permitieron sus posibilidades políticas y económicas, México participó del proceso general que se desarrollaba en otras capitales occidentales, donde la ciencia participó de la esfera pública y operó como elemento de un proceso civilizatorio, mientras se elevaba progresivamente como el discurso con mayor autoridad epistémica.

un ejemplo de la presencia del conocimiento científico en la cotidianeidad de la élite novohispana (Tanck, 1982, p. 19).

3 Esta situación indujo a la búsqueda de una sede alternativa que han estudiado Azuela, Vega y Nieto, 2009, p. 102.

4 Ernani o El honor castellano es una ópera romántica de Giuseppe Verdi (1813-1901) que se estrenó en el teatro La Fenice de Venecia el 9 de marzo de 1844.

5 La intención de instruir, así como la disposición en secciones, presumiblemente se inspiró en el Ateneo de Madrid, que tuvo también fines educativos y el mismo sistema organizativo.

6 Por literario no debe entenderse solamente a las Bellas Letras, pues su acepción entre 1730 y 1860 señala "lo que pertenece a las letras, ciencias o estudios", es decir, una cultura desarrollada en instituciones como la Universidad (Real Academia Española, 1734, Vol. II, p. 417 y Vol. V, p. 587).

Álvarez, Joaquín (2006), Los hombres de letras en la España del siglo XVIII: apóstoles y arribistas. Madrid, Castalia, p. 19.

Azuela, Luz Fernanda (2003), "La Sociedad Mexicana de Geografía y Estadística, la organización de la ciencia y la construcción del país en el siglo XIX", Investigaciones Geográficas (52), pp. 153-166, p. 153. 
Azuela, Luz Fernanda; Sabás, Ana (2009), "Naturaleza y territorio en las publicaciones del siglo XIX mexicano". En: Lértora, Celina (coord.), Geografía e Historia Natural: Hacia una historia comparada. Estudio desde Argentina, México, Costa Rica y Paraguay, Buenos Aires, Fundación para el Estudio del Pensamiento Argentino e Iberoamericano, vol. II, pp. 79100, pp. 84-87.

Azuela, Luz Fernanda; Sabás, Ana; Smith, Ana (2008), “La Geografía y la Historia Natural en las revistas literarias de la primera mitad del siglo XIX". En: Lértora, Celina (coord.), Geografía e Historia Natural: Hacia una historia comparada. Estudio desde Argentina, México, Costa Rica y Paraguay, Buenos Aires, Fundación para el Estudio del Pensamiento Argentino e Iberoamericano, vol.I, pp. 55-88, p. 61.

Azuela, Luz Fernanda; Vega y Ortega, Rodrigo; Nieto, Raúl (2009), “Un edificio científico para el Imperio de Maximiliano: El Museo Público de Historia Natural, Arqueología e Historia". En: Lértora, Celina (coord.), Geografía e Historia Natural: Hacia una historia comparada. Estudio desde Argentina, México, Costa Rica y Paraguay, Buenos Aires, Fundación para el Estudio del Pensamiento Argentino e Iberoamericano, vol. II, pp. 101-124, p. 102.

Bensaude-Vincent, Bernard (2009), "A Historical Perspective of Science and its Others", Isis, 100 (2), pp. 359-368.

Broman, Thomas (1998), "The Habermasian Public Sphere and Science in the Enlightenment", History of Science Journal, 36, pp. $123-149$.

Capel, Horacio (1993), “El asociacionismo científico en Iberoamérica. La necesidad de un enfoque globalizador". En: Lafuente, Antonio, Elena, Alberto y Ortega, Martha (eds.), Mundialización de la ciencia y la cultura nacional, Madrid, Doce Calles/Universidad Autónoma de Madrid, pp. 409-428, p. 412.

Comellas, José Luis (2003), “El espíritu de las Academias del siglo XVIII". En: Reyes, Rogelio y Vila Vilar, Enriqueta (eds.), El mundo de las Academias: del ayer al hoy. Actas del congreso internacional celebrado con motivo del CCIL aniversario de la fundación de la Real Academia Sevillana de Buenas Letras, 1751- 2001, Sevilla, Universidad de Sevilla, pp. 29-46, p. 29.

Díaz y de Ovando, Clementina (2003), Los cafés en México en el siglo XIX. México, Universidad Nacional Autónoma de México, p. 76.

Díaz y de Ovando, Clementina (1998), Los veneros de la ciencia de la ciencia mexicana. Crónica del Real Seminario de Minería (1792-1892). México, Universidad Nacional Autónoma de México, pp. 724-725.

González Bernaldo de Quirós, Pilar (2001), Civilidad y política en los orígenes de la Nación Argentina. Las sociabilidades en Buenos Aires, 1829-1862. Buenos Aires, Fondo de Cultura Económica, p. 71.
Guerra, François-Xavier y Lempérière, Annick (1998), Los espacios públicos en Iberoamérica. Ambigüedades y problemas. Siglos XVIII-XIX. México, Fondo de Cultura Económica, pp. 10-11 y p. 17.

Habermas, Jürgen (1981), Historia y crítica de la opinión pública. La transformación estructural de la vida pública. México, Mass Media, p. 84.

Hernández Franyuti, Regina (2007), “Un espacio entre la religión y la diversión: el Paseo de las Cadenas (1840-1860)", Anales del Instituto de Investigaciones Estéticas, (90), pp. 101-117, p. 102.

Hobsbawm, Eric (2003), La era de la Revolución, 1789-1848. Barcelona, Cátedra, p. 198.

Lafuente, Antonio (1998), Guía del Madrid científico. Ciencia y Corte. Madrid, Comunidad de Madrid/Doce Calles/CSIC, p. 10.

López-Ocón, Leoncio (1998), “La formación de un espacio público para la ciencia en la América Latina durante el siglo XIX", Asclepio, 50 (2), pp. 205-225.

Lynn, Michael (2001), "Divining the Enlightenment: Public Opinion and Popular Science in Old Regime France", Isis, 92 (1), pp. 34-54.

Mayer, Brantz (1953), México lo que fue y lo que es. México, Fondo de Cultura Económica, pp. 357-358.

Munck, Thomas (2001), Historia social de la ilustración. Barcelona, Crítica, p. 281.

Nathans, Benjamin (1990), "Public Sphere in the Era of the French Revolution", French Historical Studies, 16 (3), pp. 620-644, p. 624.

Perales Ojeda, Alicia (1957), Las asociaciones literarias mexicanas. México, Universidad Nacional Autónoma de México, p. 83.

Peset, José Luis (1987), "Historia de la ciencia e historia de la cultura", Linguas e Literaturas, 1, pp. 91-101, p. 87.

Peset, José Luis (2003), "Las Academias y la ciencia”. En: Reyes, Rogelio y Vila Vilar, Enriqueta (eds.), El mundo de las Academias: del ayer al hoy. Actas del congreso internacional celebrado con motivo del CCIL aniversario de la fundación de la Real Academia Sevillana de Buenas Letras, 1751-2001, Sevilla, Universidad de Sevilla, pp. 120-131, p. 122.

Pimentel, Juan (2010), “¿Qué es la historia cultural de la ciencia?", Arbor. Ciencia, Pensamiento y Cultura, 186 (743), pp. 417-424, p. 418.

Pohl-Valero, Stefan (2012), “Perspectivas culturales para hacer historia de la ciencia en Colombia". En: Hering, Max y Pérez, Amada (eds.), Historia cultural desde Colombia: categorías y debates, Bogotá, Universidad Javeriana, pp. 399-430, p. 400. 
Real Academia Española (1734), Diccionario de la lengua castellana en que se explica el verdadero sentido de las voces, su naturaleza y calidad, con las phrases o modos de hablar, los proverbios ó refranes, y otras cosas convenientes al uso de la lengua. Dedicado al Rey Nuestro Señor Don Phelipe $V$. (Que Dios guarde) a cuyas reales expensas se hace esta obra, 8 volúmenes. Madrid, Imprenta de la Real Academia Española, p. 586

Ríos, Rosalina (1994), "De Cádiz a México. La cuestión de los institutos literarios (1823-1833)", Secuencia, (30), pp. 5-32, p. 5

Sábato, Hilda (2007), "Elites políticas y formación de las repúblicas en la Hispanoamérica del siglo XIX". En: Birle, Peter; Hofmeister, Wilhelm; Mailhold, Günther; Potthast, Barbara (eds.), Elites en América Latina, Madrid, IberoamericanaVervuert, pp. 53-76, p. 56.

Saladino, Alberto (1996), Ciencia y prensa durante la llustración latinoamericana. Toluca, Universidad Autónoma del Estado de México.

Scott, Donald (1980), "The Popular Lecture and the Creation of a Public in Mid-Nineteenth-Century America", The Journal of American History, 61 (4), pp. 791-809.

Suárez, Laura (2005), “Los impresos: construcción de una comunidad cultural. México, 1800-1855”, Historias, (60), pp. $77-92$, p. 85
Tanck, Dorothy (1982), "Justas florales de los botánicos ilustrados”, Diálogos, 18 (106), pp. 19-31, p. 19

Vega y Ortega, Rodrigo (2010), "Los establecimientos científicos de la ciudad de México vistos por viajeros, 1821-1855", Araucaria, 12 (24), pp. 3-38, p. 5.

Vega y Ortega, Rodrigo (2014), La naturaleza mexicana en el Museo Nacional, 1825-1852. México, Historiadores de las Ciencias y las Humanidades, A. C., p. 103.

Yanni, Carla (2005), Nature's Museums. Victorian Science and the Architecture of Display. New York, Princeton Architectural Press, p. 24

Zamudio, Graciela (2011), “La práctica naturalista de los expedicionarios Martín de Sessé y José Mariano Mociño (17871803)". En: Azuela, Luz Fernanda; Vega y Ortega, Rodrigo (coords.), La geografía y las ciencias naturales en el siglo XIX mexicano, México, Universidad Nacional Autónoma de México, pp. 39-50, p. 39-41

Zanolli, Betty (2000), “El Conservatorio Nacional de Música: 130 años de historia", Conservatorianos, 1 (1), pp. 5-11, 6 